\title{
Más allá y más acá del papel en blanco. El café, el bar y las tertulias en el "fin de siglo" mexicano
}

Juan Pascual Gay

El Colegio de San Luis

\section{Resumen}

En este ensayo encontraremos una indagación sobre la democratización de los espacios públicos y la relación de este fenómeno con otro más íntimo: el despliegue de las ideas y la escritura. El texto parte del último cuarto del siglo XIX, exponiendo el evidente contraste entre las clases sociales en México. El autor expone la caracterización de algunos de los clubes más importantes frecuentados por la alta sociedad, su lujo y elegancia, en contraste con las cantinas, sitios de distracción para el pueblo.

Luego, lugares como el bar y el café, donde se desarrolló la tertulia, cobraron importancia a raíz de la diversidad de la gente que asistía a ellos, permitiendo así la convivencia de los diferentes grupos sociales. Estos recintos albergaron a los escritores del romanticismo tardío, lo mismo que a modernistas, a los integrantes de Contemporáneos, de Taller y a la generación de Medio Siglo. Producción literaria que en ocasiones se gesta, se desarrolla o se transforma en estos sitios de discusión y reflexión.

Palabras clave: café, bar, tertulia, literatura autobiográfica, espacios públicos.

\section{Abstract}

In this work we'll find an investigation about the democratization of the public spaces and the relation between this phenomenon with another 
more intimate: the display of ideas and writing. The text begins from the last quarter of the XIX century, exposing the evident contrast between the social classes in Mexico. The author exposes the characterization of some of the more frequented clubs by the high society, their luxury and elegance, in contrast with the pubs, sites for the people's distraction.

Subsequently, places like the bar and the coffee bar, where the gathering was developed, became more important because of the diversity of people who assisted to them, allowing the coexistence of different social groups. This places accommodated the writers of the late romanticism, modernists, members of the Contemporáneos, Taller and the Generación de Medio Siglo. Literary production that sometimes is grown, developed or transformed in this sites of discussion and reflection.

Keywords: Coffe bar, gathering, autobiographic literature, public spaces.

$\mathrm{E}$ n el primer impulso modernizador en el último cuarto del siglo XIX, la ciudad de México se pobló de una nueva clase social, los burócratas, que pasaron a engrosar el número de lo que comenzó a llamarse clase media en virtud del esfuerzo de la administración porfiriana por burocratizar la función pública. Esta clase media chocaba frontalmente con los intereses y ambiciones de la clase acomodada, constituida habitualmente por las familias aristocráticas o de abolengo que, en algunos casos, se remontaban a la Colonia y que se comportaban como una sociedad al margen o dentro de la sociedad con la que apenas tenían otra relación que la de solicitar servicios; una sociedad que se regía por sus propias normas, siempre dispuesta a marcar los límites de clase por su posición económica o por su influencia política. Pero sin duda la clase social más numerosa que pululaba por las calles de la gran ciudad era la del proletariado, constituida por trabajadores venidos de todos los lugares de la república en busca de fortuna, que vivían en muchas ocasiones en condiciones 
infrahumanas. Los espacios de la ciudad de México estaban perfectamente delimitados según los ocuparan unas u otras clases sociales: así, la colonia de la Candelaria, la de la Soledad o la de San Pablo, retratada por Ignacio Manuel Altamirano con pinceladas que, por momentos, recuerdan al naturalismo de Zola:

Más allá del Zócalo y de Plateros [...] la anemia, la melancolía, los murmullos prosaicos, el hormigueo de los pobres, la pestilencia de las calles desaseadas, el aspecto sucio y triste del México del siglo XVII, las atarjeas asolvadas, los charcos, los montones de basura, los gritos chillones de las vendedoras, los guińapos, los coches de sitio con sus mulas éticas y, sobre todo, pasando a veces un carro de las tranvías como una sonrisa de la civilización, iluminando ese gesto de la miseria y de la suciedad.

Y más allá todavía, por las regiones desconocidas de la Soledad, de Tomatlán, de San Pablo y de la Candelaria de los Patos, al este y al sudeste; de San Antonio y de Necatitlán al sur, y de santa María Peralvillo al norte, la salvajería, la desnudez, las casas infectas en que se aglomera una población escuálida y muerta de hambre, familias enteras de enfermos y pordioseros, el proletarismo en su más repugnante expresión. El municipio apenas cuelga por allí un farol de aceite, por la noche, y la policía envía a sus gendarmes más bien para acechar que para cuidar (82).

Espacios marginados donde el ser humano vivía postrado y humillado contrastaban con el elitista y aristocrático Jockey Club, situado a unos pasos precisamente de la Candelaria:

A quelques pas de là, à une dizaine de rues de la place centrale, se truvait le Jockey Club, la Mecque indiscutible de la Haute société. Le club occupait la demeure la plus opulente de la capitale, un édifice à la facade bleue et blanche qui avait appartenu à une grande famille de la colonie. Son patio, décoré de palmiers et de fleurs autour d'une grande fontaine évoquait l'Andalousie. Les pièces intérieures avaient de miroirs qui 
allaient du sol au plafond. Le directeur du Jockey club était Manuel Romero Rubio, beau père de Porfirio Diaz et les membres étaient triés sur le volet parmi les riches industriels, les hommes politiques et les grands propriétaires terriens (Panabière, 1993 : 92).

Las clases marginales concurrían las numerosas cantinas y pulquerías a falta de otros lugares de esparcimiento, donde los efectos del alcohol embrutecían a sus clientes y parroquianos, un problema ańadido a las paupérrimas condiciones de vida, que si bien solventaban con frecuencia las necesidades de notas y crónicas rojas de las redacciones de los periódicos, también engrosaban los registros policiales: "Es verdad que las cien cantinas y mil pulquerías que se ostentan cínicamente por todas partes, atraen también alguna concurrencia, pero ésta es solo de hombres, y las novedades que suelen presentarse no pertenecen a la bella literatura, sino a los registros de la policía, a los cronistas de las cárceles de ciudad, a los alcaides" (Altamirano, 1986: 81). Muy diferentes eran las distracciones que el Jockey Club brindaba a sus miembros, todos ellos distinguidos por el hecho de pertenecer a ese club, que se ejercitaban en deportes como el Polo, las carreras de caballos y la caza, según la más estricta tradición británica. El Jockey venía a heredar, no tanto por la práctica de un deporte concreto sino por su origen exclusivo y aristocrático, el glamour y el encanto de otras sociedades que le precedieron como el Mexico Cricket Club, fundado en 1827, que en 1904 se unió al San Pedro Golf Club para organizar el Mexico City Country Club. El Jockey Club abrió sus puertas en 1881; las repercusiones de sus actividades recreativas y deportivas fueron inmediatas no sólo en la capital sino también en el resto del país, popularizándose las carreras de caballos en Veracruz, Amatlán y León, más tarde en Guadalajara y Chihuahua. Hacia 1890, las carreras de caballos eran el evento deportivo que más expectación levantaba en el país (Beezley, 1989: 26-31). En 1892, el Jockey Club se instaló en la Casa de los Azulejos, vetusto edificio que data de 1524, junto al 
Palacio de Bellas Artes; entre sus muros y en lo amplio de sus salones se reunió la sociedad aristocrática del porfiriato hasta 1915; por sus correderos y patios interiores desfilaron los modernistas Manuel Gutiérrez Nájera, Justo Sierra, Manuel José Othón o Salvador Díaz Mirón; más tarde, acogió a algunos miembros del Ateneo como José de la Cortina, Andrés Quintana Roo y Ángel Calderón de la Barca; también cobijó a los Contemporáneos como Xavier Villaurrutia, Carlos Pellicer y Salvador Novo; finalmente, sus mesas congregaron a los escritores del Medio Siglo como Tomás Segovia, Juan García Ponce e Inés Arredondo. La Casa de los Azulejos fue desde el siglo XIX un centro muy activo tanto para escritores como para artistas; lugar de reunión, pero también de ensimismamiento; espacio convocativo, pero también evocativo; presente, pero también memoria de un pasado que sus piedras recuerdan a cada momento. Aunque sus paredes y techos contemplaron en su interior todo tipo de actividades, desde las aristocráticas del Jockey Club hasta las proletarias cuando fue reconvertido en Casa del Obrero Mundial, acabó por devolver su presente y su historia a escritores y artistas.

La dicotomía entre estos espacios creó sus tipos específicos, fácilmente reconocibles para la mayoría, como observa Amado Nervo:

El snob mexicano sería, por ejemplo, el que de cualquier manera se instalase en el zaguán del Jockey para que sus conocidos le viesen ahí y le juzgasen que pertenecía al Club, con lo cual, por lo demás, nada ganaría $[. .$.

Poco menos de lo que pasa con esa palabrita que tiende a generalizarse mucho, porque, por desgracia, bajo su denominación cabe una clase numerosa, acontece lo que con esta otra; bohemio, que por extensión se ha aplicado a una clase muy numerosa de sonadores [...]

El bohemio de México es muy distinto del de París; se le parece en lo negligente... y en lo pobre; pero se le diferencia en muchas otras cosas. Algunas veces escribe; otras, ni aun sabe escribir. Trasnocha sin objeto, vive el día y lo caracteriza la falta absoluta de aspiraciones. 
En tanto que el hambre no lo aguijonea, sonríe, y cuando el hambre lo aguijonea hace filosofía. El principal componente del carácter bohemio es la negligencia netamente latina, y dicho está con eso que el bohemio mexicano se pinta solo para no hacer nada (539-540).

El snob y el bohemio definen los espacios que frecuentan, aunque también es cierto que en determinado momento es el espacio mismo el que alienta y determina sin exclusividad la presencia de estos tipos:

Acabo de ver en una de las calles céntricas de la capital una cantina recién pintada y decorada, que lleva el sugestivo y peregrino nombre de Cantina modelo.

Vi el gran letrero y me quedé pensativo, advirtiendo que no fueron burlescas mis meditaciones.

Cantina modelo, me dije... ¿Y por qué no? Si una cantina es sitio donde se origina el mayor número de abusos posibles: intoxicaciones lentas, riñas, suicidios, enfermedades tremendas, claro es que necesita más que ninguno otro atender a la perfección.

Pero... ¿cuál será el arquetipo que puede perseguir una cantina que pretende ser modelo? Vamos a ver:

Se podría, en primer lugar, suprimir el refino con palo de Campeche y gotas amargas, aun a riesgo de no vender copas de cognac a seis centavos.

Se podría, en segundo lugar, suprimir la grosella de azúcar moreno enfriada con un conato de hielo y mezclada con otro conato de seltz.

Se podría, asimismo, no llamar pan al de ciertos sandwiches, ni tinto a la cosa oscura con que se hacen ciertas sangrías, sino llamar al pan, pan, y al vino, vino...

Y se podría... una infinidad de cosas.

Hemos llegado a un tiempo en que todo se falsifica, y el fraude ya ni sorprende ni enoja. Tácitamente aceptamos todas las mistificaciones posibles, y hoy por hoy puede decirse que la bebida espuria 
no solo ha usurpado el nombre a la legítima, sino que la burla y la escarnece (Nervo, 1991: 607-608).

Estos breves trazos no hacen sino mostrar las profundas desigualdades que existían entre los habitantes de la misma ciudad, como afirma Panabière:

Si les divertissements, jeux et plaisirs, désirs rëalisés en commun, témoignent d'une telle indifference, alors qu'ils devraient être au contraire le lieu et l'espace de la recontre et d'un imaginaire collectif, l'aire de la cultura fut au temps du Porfiriat la champo où la séparation entre les clases sociales fut la plus profonde. Les clivajes que se sont produits alors on marqué pour longtemps la cultura urbaine et nous vivons encoré les préjugés et les résultats de ces différences. Le prolétariat, la clase moyenne et l'élite capitaliste de la société, toutes les clases s'enfermèrent dans leur domaine culturel, hermëtiquement cloisonné et hostile à tout ce qui se passait ailleurs. Des indentités particulières et diverses se développèrent au sein d'une même population, et sans qu'il soit encoré question de pluralité avouée, il exista dès lors non pas "une" cultura, mais "des" cultures dans le contexte urbain (95).

En la Guía general descriptiva de la república mexicana de 1899 se establece una cartografía de la ciudad, más social que geográfica, donde se señala las zonas aconsejables para el paseo y entretenimiento de las familias bien:

Pocas capitales del mundo podrán vanagloriarse de poseer tan hermosos parques y tan frondosos bosques artificiales como la vieja Tenochtitlán; parques y bosques, jardines y alamedas, que por desgracia se ven, en su mayor parte, solitarios y tristes, algunos frecuentados por la clase baja del pueblo, que con su desaseo habitual hace huir de ellos a las familias decentes.

La gran plaza de la Constitución [...] se prestaba a la concurrencia de las familias; pero el pueblo [...] lo invalidó y, con sus costumbres 
poco edificantes, lo hizo antipático a las señoras y aun a los caballeros [...] (VVAA, 1959: 308).

La fisonomía de la ciudad de México adquiere bajo el porfiriato unos rasgos quiméricos entre los que sobresalen el cosmopolitismo y, a la vez, una extraordinaria diversidad y mezcolanza humana y social: transformada en polo de atracción no sólo de la república mexicana sino también de algunos países latinoamericanos y europeos, al tiempo que aumenta su población en progresión geométrica, las diferencias y las distancias entre las clases sociales aumentan hasta convertirse en verdaderos muros de contención que impedían la movilidad social. Unos versos de José Joaquín Fernández de Lizardi expresan esa distancia dramática entre clases sociales a mediados del siglo XIX:

Hay una casa de pobres... ¿una dije? Miente el labio, Que hay tantas, amigo, hay tantas, Que da dolor el pensarlo; Y lo peor es, que hay de ricos Innumerables palacios; Pero siempre la miseria Llorosa los ve cerrados (312).

José Luis Martínez, autor de un texto intitulado con elocuencia "Estar en el mundo, 1889-1910", sitúa un cambio de estética en la última década del siglo XIX: el romanticismo que había devenido pintoresquismo y color local, troca por la nueva sensibilidad que se había iniciado con el Ismaelillo, de José Martí, en 1882. Martínez localiza los primeros síntomas de la nueva enfermedad que se llamó modernismo en la revista La juventud literaria (1887-1888), en cuyas páginas:

[...] se manifiesta ya el cruce de las dos épocas y las dos sensibilidades, y el inminente desprendimiento de la nueva generación. Al lado 
de los últimos románticos y de Altamirano y sus discípulos, aparecen reunidos por primera vez muchos de los escritores, entonces jóvenes, que estaban realizando, acaso sin proponérselo, la revolución literaria: Luis G. Urbina, Jesús E. Valenzuela, Manuel Gutiérrez Nájera, Manuel Puga y Acal, Salvador Díaz Mirón, Federico Gamboa, Carlos Díaz Dufoo, Manuel José Othón, etc. (1062).

Desde ese momento, se suceden publicaciones que aglutinan a los artistas y escritores adeptos a la nueva estética: la Revista Azul (18941896) y, poco más tarde, la Revista Moderna (1898-1911). Constituidos los poetas simbolistas y parnasianistas franceses como sus dioses mayores, los modernistas mexicanos optaron por imitar no sólo la nueva poética sino los modos de vida de aquéllos. De esta manera, como concluye José Luis Martínez, "Los escritores y artistas del grupo básico de la revista [Revista Moderna] decidieron, pues, ser poètes maudits a la manera francesa, y llevar una vida de bohemia que rompía con la moral de la época. El rigor y la disciplina se la reservaron exclusivamente para sus creaciones artísticas" (1069.). Esta misma ambigüedad a la hora de decantarse por el viejo romanticismo o por el nuevo modernismo la vivieron los artistas de manera individual; es reveladora la semblanza de Enrique Fernández Ledesma a propósito del poeta Luis Gonzaga Ortiz: "Don Luis acababa de llegar de Europa. De allá había traído primores de arte e ideas de inquietud. $\mathrm{Su}$ derretido entusiasmo renovóse en el Viejo Mundo. Su sentido de sociabilidad se aguzó en las estadías — para él inolvidables — de París y Roma. Vino a México suspirante, pero alerta, con la nostalgia de la bohemia en Montmartre y el veneno de los cenáculos [...]” (126). Seguramente los hábitos de vida bohemia fueron una de las vías por las que esas barreras sociales comenzaron, si no a caer, por lo menos a flexibilizarse, a agrietarse, a resquebrajarse. No era raro encontrar a Federico Gamboa en determinadas cantinas y, al mismo tiempo, frecuentar el bar el Jockey Club o las nuevas cervecerías que comen- 
zaban a poblar la ciudad de México. Si las costumbres y celebraciones sociales propiciaban la inmovilidad social, los nuevos espacios de convivencia, como el café, el bar o la cantina, comenzaron a favorecer la apropiación de esos espacios públicos por una representación socialmente heterogénea de los habitantes de la ciudad. La siguiente etapa fue la apropiación o privatización de esos lugares por parte de sus parroquianos. La literatura autobiográfica de esta época da cuenta de la presencia de estos espacios en la vida cotidiana de sus autores, donde lo público comienza a confundirse con lo privado, donde las barreras entre clases sociales parecen difuminarse. En realidad, no es tanto que los espacios públicos se trasformen en privados o viceversa, sino que sus vagos e imprecisos contornos modifican el sentido de la intimidad.

Nuevos modos, hábitos y costumbres trajo la ciudad moderna para sus habitantes, propiciando de esta manera un cambio en unos pocos años que de otro modo hubiera durado décadas: los espacios citadinos se abrieron renunciando así a las antiguas fórmulas que restringían su acceso en virtud del linaje o del poder político y económico, se democratizó la vida cotidiana al alentar una convivencia en los lugares públicos que borraban y abolían las antiguas barreras de clase social; los medios de comunicación llegaron al hombre común y corriente que comenzó a edificar el concepto de ciudadanía. La ciudad moderna propició todos estos cambios en un momento en que la velocidad era metonimia de urbe. Así radiografiaba Ignacio Ramírez estos cambios de época:

Los héroes de Homero son bandidos; los dioses, ficciones; los bonzos, dementes; los amores pastoriles, una diversión de nińos; las desgracias de los reyes forman el placer de los pueblos; y ya en escasos hogares se consagra al sacerdocio doméstico la inocente y severa matrona; tales mujeres, tales hombres, y las tempestades revolucionarias, y los ferrocarriles, y el telégrafo, y la fotografía, y los antiguos monstruos 
estremeciéndose en sus lechos geológicos, y los soles adornados con las diversas cintas del iris, y los nuevos universos que más allá de la vía láctea se asoman; todo esto tiene que reproducir hoy la elocuencia y la poesía. Su voz de gigantes se llama la imprenta (92).

Pero la ciudad además proporcionaba una imagen semejante a la del papel o la cuartilla del escritor hasta llegar a constituirse esta comparación ("la cuartilla como una ciudad; una ciudad, como una cuartilla”) en un lugar común:

Por eso, para comprender a una ciudad, basta con imaginar un cuadrado pues no hay que olvidar que las ciudades son - por tradición - cuadradas. Basta con trazar una imaginaria estructura en la hoja en blanco en la cual las calles sean líneas de palabras, los callejones tal vez paréntesis, corchetes los pasos a desnivel, el adverbio una farmacia, adjetivo el mercado, conjunción la gasolinería, errata el Sanborn's y la eterna duda de saber si nuestra sombra nos seguirá al doblar la esquina o la página. Y entonces, un cuarto de hotel, la tarde, un amor furtivo pero jamás prohibido, es sólo una nota de autor a pie de página: esa es la ciudad del escritor, un simple plano dentro de una estructura literaria en la que el texto es ciudad que puede leerse o recorrerse según las perversiones del lector o del peatón (Leyva, 1997: 89-90).

Prosperó, pues, un movimiento en el que el yo era el eje dinamizado por algunos rasgos propios de la modernidad: la conjunción de la relevancia de lo autobiográfico situado en el nuevo espacio de la ciudad mecanizada e industrial produjo un aceleramiento en la visión misma de ese yo que comenzó a debatirse entre lo privado y lo público, como prueba el género fundador de la literatura propiamente hispanoamericana, la crónica. No son mera coincidencia los numerosos títulos que alrededor de 1900 aparecen teniendo como protagonista a la ciudad de México o, más precisamente, la vida en la ciudad: en 
1906 Guillermo Prieto publica Memorias de mis tiempos y Antonio García Cubas, El libro de mis recuerdos; Juan de Dios Peza, De la gaveta intima. Memorias, reliquias y retratos (1900); Vicente Riva Palacio, Memorias de un impostor (1872); Luis González de Obregón, Las calles de México (1922), etc. Lo importante es subrayar que desde el cuadro de costumbres y la crónica, que actuaron al principio como filtros literarios a través de los que fue emergiendo la subjetividad, se pasó a la escritura autobiográfica manifestada a través de memorias y autobiografías, o por medio de diarios. Era natural que la ciudad y los lugares preferentes de la bohemia modernista, como el bar y el café, ocuparan un espacio privilegiado en su escritura tanto pública como privada, porque el bar, no así el café considerado como lugar de encuentro, se introdujo en México en la época de Porfirio Díaz:

Como existían en esta calle lugares excelentes para comer bien, también los había superiores para el buen beber. Sitios elegantes y cómodos, tanto para las personas ricas como para la bohemia limpia que gustaba de mojar la palabra en el vino caro, lugares de poco más o menos para los que no tenían mucho dinero con qué darle placer a su vicio o a su gusto. Las cantinas o bares a la manera americana, sobria y pulcra, no proceden en México sino de la era en que gobernaba el general don Porfirio Díaz. Antes de esos años pacíficos no eran conocidos tales establecimientos para la bebienda (Valle-Arizpe, 1980: 501).

Del Valle-Arizpe procede a un recuento de las cantinas más reconocidas de la ciudad de México: el Salón Peter Gray, que tuvo el acierto de introducir las bebidas compuestas desconocidas hasta ese momento en México, así se conocieron los cock-tails, los hihg-balls, los draks o los mint-jules, disfrutó de dos épocas: la primera situado en la esquina entre el Portal de Mercaderes y Agustinos; la segunda, en la esquina de Plateros con el mismo Portal de Mercaderes; el Salón Wondracheck, ubicado al final de la calle del Espíritu Santo, frente al 
Hotel de la Gran Sociedad; el Silvayn, que gozaba de una cantina de gran reputación al incluir en su carta vinos de los más importantes viñedos franceses y que, además, tenía fama de que su concurrencia era la que estaba más a la moda, reproduciendo los diseños de los trajes y atuendos, así como los peinados y arreglos personales, que procedían directamente de París y Londres, y cuyas propuestas y novedades se podían consultar en las páginas de La moda elegante. También había bares con una clientela propia y exclusiva, cuyos dueños no dudaban en mostrar su recelo frente al desconocido o ante quien desentonara con el ambiente del local: en la casa número siete del Coliseo se encontraba situada la Nueva Reforma, cuyo nombre permite sospechar que se rotuló sobre el antiguo Reforma; justo enfrente estaba La Noche Buena, cuyos habituales eran toreros o cómicos del Teatro Principal. En la esquina suroeste de la Avenida 16 de septiembre y Colegio de Nińas, estaba La Alhambra que a diferencia de las otras cantinas se caracterizaba por acoger detrás de sus puertas a todas las clases sociales; como ésta, el Salón Monte Carlo, era un espacio diverso y heterogéneo, situado en los bajos del Colegio de Niñas (Valle-Arizpe, 1980: 501-509). Bares y cantinas, pues, propiciaron la mezcla de diferentes clases sociales, el revoltijo de profesiones, el fárrago de edades; en las menos elegantes, también el tráfico sexual y la promiscuidad. La confusión y el alboroto eran parte del ambiente de estos establecimientos, como el juego y las apuestas, pero todo ello produjo algo que transcendía con mucho las actividades concretas que allí se desarrollaban: la liberalización de las costumbres y la flexibilización de las estructuras sociales; unos espacios que, a pesar de caracterizarse a veces por su sordidez, fomentaban la individualidad, el reconocimiento del individuo por lo que era, no por su procedencia o por su estatus económico o por su oficio. Junto al bar, el café tuvo una influencia social similar. Lo que ofrecían, en realidad, esos espacios a los grupos de poetas y artistas no era únicamente el exotismo de las recientes 
bebidas importadas de Estados Unidos, ni el juego furtivo, sino algo más no exento de cierto clandestinaje: la conspiración y la conjura; aditamentos y accesorios suficientemente atractivos para sostener las tertulias en torno a las cuales se congregaba la bohemia artística y cultural del fin de siglo. En México, a lo largo del siglo XIX, hubo tertulias de toda clase y condición. García Cubas es quizás el autor que le ha dedicado mayor atención a estas reuniones que cubren un amplio abanico de posibilidades y necesidades: desde las tertulias en casa de familias en torno a las que se juntaban familiares, amigos y vecinos, hasta los cenáculos propiamente literarios que tenían lugar en bares y cafés. García Cubas describe en clave de moralidad el ambiente de las tertulias familiares, interesado en todo momento en subrayar el buen trato y la afabilidad de esas reuniones que discurre entre las conversaciones políticas de los mayores y los juegos de salón de los jóvenes:

Vas a concurrir a una de esas tertulias que sirven de solaz y entretenimiento a los jóvenes, durante las noches de los miércoles y sábados en que los teatros cierran sus puertas, por ser aquéllos días de correo. La casa en que voy a conducirte es de las principales de la ciudad y se halla situada en una calle céntrica. La familia que la habita se distingue por su trato fino y esmerada educación, de abolengo trasmitida, siendo tan afables el señor y la señora, como apuestas y elegantes sus tres hijas, de blondas cabelleras, finísimos rostros y cuerpos enhiestos como palmeras [...].

De esas jóvenes, las que se distinguen por sus progresos musicales, distraen a la concurrencia, si son discípulas de León, con brillantes fantasías del albergo de Liszt ejecutadas en el piano, y si de los maestros Flores y Balderas, con su hermoso canto interpretando, ora, arias como las de El Barbero de Sevilla, Semiramis, Tancredo o Mahometo II, ora, tiernas y sentimentales romanzas, como El Ave María, de Baca y la famosa Stella Confidente.

$\mathrm{Al}$ concierto sucede el baile, durante el cual reina gran animación 
y una confianza plausible, como que no traspasa los límites de la decencia (244).

Pero estas tertulias y reuniones poco tienen que ver con las más conocidas de las de artistas y escritores que configuraron el carácter de la bohemia de "fin de siglo". Irma Contreras García cartografía el itinerario cotidiano de Manuel Gutiérrez Nájera donde sobresalen los cafés y los lugares de reunión; un itinerario más cercano, sin duda, a lo que debía ser el de la bohemia modernista:

Era asiduo concurrente al "Café de La Concordia", centro de reunión de la flor y nata de la sociedad de entonces; al elegante establecimiento del barbero francés Pierre Micoló, a donde los "gomosos" y "los gallos de Micoló" (jóvenes de la clase acomodada) acudían para enterarse de las últimas novedades; al restaurante "La Maison D’or", de don Carlos Récamier, quien aderezaba exquisitos platillos que eran el deleite de los asistentes y popularizó "La Sorpresa" y el "Jockey Club". Saboreaba con placer, según su propia confesión, "una soberbia cafetera llena de delicioso moka, dos tarros de cristal con licor de la Cartuja, una caja abierta de codiciables puros, frescos todavía por las húmedas brisas de mar" y la amena conversación de un amigo con quien compartía sus gustos y temas favoritos (17).

Andrés Trapiello enumera tres motivos por los que los literatos, bohemios o no, acudían puntualmente a las tertulias:

$1^{\circ}$, porque en sus casas respectivas hacía mucho más frío que en el café; $2^{\circ}$, porque casi todos ellos o estaban solteros, o enredados con modistillas o eran desgraciados en sus matrimonios; y $3^{\circ}$, porque quienes iban a una tertulia seguramente eran partidarios de $a$ ) la elocuencia, $b$ ) la vida social, $c$ ) los escalafones y $d$ ) pasar el rato al precio que fuese, para hacer buena la máxima del bohemio: "como fuera de casa, en ningún sitio" (8). 
Pero también las tertulias tenían lugar en las casas, aunque más habitualmente buhardillas o chambres de bonne durante el periodo modernista que abrazó abiertamente la bohemia; unas reuniones que Alfonso Zepeda Winkfield ha dejado retratadas en el soneto titulado "De La Boheme":

En la mísera y lúgubre buhardilla

Donde todo respira desconsuelo;

Los bohemios ahogando su desvelo

Bailando están la clásica cuadrilla (61).

La importancia de acudir al café, en realidad, trascendía las conversaciones y debates que tenían lugar entre sus cuatro paredes, también la altura o calidad intelectual de los contertulios; la tertulia tenía un valor en sí mismo semejante entonces al que tenía cualquiera de las bellas artes. El artista, en el café, exhibía su propia personalidad transformada ahora en objeto estético, como dice Elizabeth Wilson: "was a stage for that most ephemeral, yet infinitely repeatable performance: the performance of personality" (37); algo que también recordaba Ricardo Baroja: "el gabinete de trabajo de los escritores, taller de los dibujantes" (51). Asistir a una tertulia por primera vez tenía algo de rito iniciático y, además, era también el camino más corto para alcanzar cierta notoriedad literaria, como entendió pronto José Juan Tablada:

El adentramiento en el mundo literario lo hizo a pasos firmes hasta llegar al recinto sagrado. Convivió estrechamente con individuos hoy desconocidos. Como José Bustillos y Guillermo Vigil y Robles, así como con otros que sí gozan de renombre o al menos son familiares: Ángel del Campo, Federico Gamboa, Bernardo Couto, Alberto Leduc, Francisco Olaguíbel, Balbino Dávalos, Antenor Lazcano. Con ellos participó en tertulias literarias, complementadas con charlas que versaban en los temas de actualidad, y con los cinco últimos 
frecuentó, además, los paraísos artificiales (Lozano Herrera, 1995: 76).

Ramón Gómez de la Serna ha dejado una estampa inolvidable del café titulada "Dignificación del Café":

El Café es una cosa seria, casi todos los Cafés. El gran Verlaine, magnífico Papa-Rey, los bendijo y los dejó benditos para siempre, encontrando en ellos el respaldo en que echar la cabeza, aunque cometiendo la equivocación, discúlpanle por lo desesperado que se está en la vida, de tomar ajenjos con goma (goma terrible, como hecha de la sustancia de esos "gomas" de que mueren los sifilíticos y que no sé por qué me parece que entran en la composición de la goma cáustica y terrible que anisa el ajenjo). Beethoven también lo bendijo, y Braun von Braunthal se lo encuentra en un rincón del Café fumando una larga pipa y cerrando los ojos (1999: 235).

Estas palabras, más apologéticas que descriptivas, reivindican al café en tres aspectos que, en realidad, convienen más a la tertulia que propiamente al espacio del café: primero, la posibilidad de consumir ajenjo, bebida que por sí misma evoca la bohemia simbolista y postsimbolista parisina de la segunda mitad del siglo XIX, conocido también como absenta o fée vert, donde era el enervante privilegiado y el mecanismo más cómodo y a la mano para acceder a los paraísos artificiales, Alfonso Zepeda Winkfield tiene un poema de 1903 titulado precisamente "Gotas de ajenjo":

Brotad ¡oh versos! Del cerebro mío

Musa bohemia inspira mis canciones,

Huya de mi alma el rencoroso hastío

Y retornen a mí las ilusiones.

Quiero embriagarme ¡oh musa! En tus placeres $\mathrm{Y}$ vivir en tus mundos orientales 
Adorado por pálidas mujeres

De albas manos y senos ideales (57).

Antes ya se habían ocupado de literaturizar a propósito de la absenta tanto el Duque Juan como Bernardo Couto Castillo. El primero, en un texto titulado "Absinthe", decía cosas como estas:

Estoy frente a la mesita de mármol, pensando en cosas idas; en mi copa ondea el absinthe con claridades opalinas y resplandores tibios, en tanto que la luz irisa las burbujas que sobrenadan en la superficie...

Un vapor fosfóreo se levanta del líquido, rodea la copa y se difunde en mi estancia. En ese vapor hay muchos puntos luminosos que giran, voltejean y se pierden después, fingen caudas ondulantes, del color del ámbar, unos; otros, se van oscureciendo rápidamente; después... las márgenes crecen, la copa de cristal finge un lago de oro que se incendia a los reflejos de la luz; entonces los puntos luminosos se transforman en rostros vagamente delineados; las caudas de oro, son cabelleras desatadas, rubias, como el champagne; y las caudas negras, son cabelleras de sombra (Gutiérrez Nájera, 1896: 45).

Por su parte, Couto Castillo, dentro de la sección "Poemas locos", colaboraba con la prosa "La canción del ajenjo", donde a través de un diálogo entre el enervante y el poeta concluye con un reconocimiento de sus efectos perniciosos: “¡Insensato! ¡Del fondo de ese vaso levántase irguiéndose y desarrollándose la verdosa serpiente del deseo — la serpiente de ojos de zafiro- la serpiente del deseo de lo imposible, porque tu destino, tu singular, tu errabundo destino, para siempre te separó de todas las venturas!" (77).

En segundo lugar, el café se vuelve un espacio seductor y persuasivo por su independencia propiciada, a veces, al calor del ajenjo como se deduce de esos "rostros iluminados como arcos voltaicos", un lugar donde compartir y participar de manera desinhibida; por 
último, el reconocimiento del café como el corazón de la ciudad donde se congregan los elegidos y se respira una atmósfera a la vez aristocrática y decadente. También Zepeda Winkfield hace gala de ese espíritu gótico y noble pero ya consumido que caracteriza a cierto modernismo:
Apurando mi copa de ajenjo llameante
Y enhebrando sueños en mi fantasía,
Miro a la canalla que pasa triunfante
Insultos lanzando con cólera impía (71).

Las tres características subrayan un espacio sacralizado regido por sus ritos y códigos particulares, destinados antes a una cofradía o sociedad secreta que a un grupo de amigos o allegados, regida por sus propias leyes o mandamientos, como los que se encargó de registrar el autor de las Greguerías (Gómez de la Serna, 1999: 202).

Además de temas artísticos, literarios y políticos, la tertulia funcionaba como un transmisor de las noticias que la actualidad iba generando, donde cada grupo mostraba sus adhesiones hacia uno $u$ otro periódico según sus convicciones o posturas ideológicas. Hacia 1900, el Distrito Federal es una zona que cuenta con un registro de 477,000 habitantes, a la ciudad de México pertenece 60 por ciento de esa población; "las tasas de analfabetismo eran muy elevadas: el 14 por ciento de la población mexicana sabía leer y escribir en 1895 y el 20 por ciento en 1910. El D.F. tenía el índice de analfabetismo más alto del país, en 1895 se calculó 38 por ciento y llegó 50 por ciento en 1910" (Pérez-Rayón, 2001: 35). Florance Toussaint indica que los periódicos circulaban entre 10 por ciento de la población debido a diferentes motivos, la escasez y precariedad de las comunicaciones, la dispersión geográfica de la población, los bajos jornales que impedían la adquisición de la prensa, etc. (67-71). Pero como señala Fernando Escalante Gozalbo: "Lo importante no eran los lectores, sino 
las tertulias y los comentarios callejeros. Las noticias se sabían por los gritos de los vendedores y por la charla de los cafés, por frecuencia por la lectura en voz alta" (269). Más precisa es Nora Pérez-Rayón Eluzundia:

En el siglo XIX las posibilidades de recreación y esparcimiento no eran de ninguna manera las del siglo XX: no había televisión, ni radio; el cine apenas comenzaba, las ciudades eran pequeñas y los vecinos permanecían en contacto constante. Las tertulias caseras, las reuniones en las tiendas de abarrotes, en los molinos, en los cafés, en las cantinas, en los portales y zócalos permitían intercambios de información y hacían en cierto grado de la política un asunto del común (36).

A partir de 1885 la prensa capitalina se diversificó en sus propuestas políticas, aunque la mayoría se tornó abiertamente anti-porfirista: el espectro de intereses de los periódicos del momento representa el amplio espectro de las ideologías dominantes: desde los medios abiertamente progubernamentales como Patria, de Ireneo Paz, o La Prensa, de José María Vigil, hasta aquellos que después de haber gozado del beneficio de las subvenciones y subsidios del gobierno cambian de orientación política y se enfrentan al régimen de Porfirio Díaz, como Reforma y el Diario del Hogar, de Filomeno Mata, que se suman así a otros medios liberales que desde el principio fueron antigubernamentales como El Monitor Republicano, El Hijo del Abuizote y a los conservadores El Tiempo, La Voz de México y El Nacional (Pérez-Rayón, 2001: 29). A finales de la última década aparece El Imparcial que permitió aumentar el número de lectores al bajar los costos y al proponer una oferta más atractiva que residía en un material de lectura más diversificado que combinaba las notas informativas con la distracción y el recreo. Pérez-Rayón dibuja a grandes trazos los rasgos de esta prensa: 
Para 1900 los grandes periódicos de la capital contaban con cuatro páginas y el número de la edición dominical, en el caso de El Imparcial, se ampliaba a ocho. Se observa el predominio de material noticioso —el reportaje — y la inclusión de relativamente pocos artículos de fondo; por excepción algo firmado y en general con seudónimo. Aproximadamente un 30 por ciento del espacio lo ocupaba la publicidad; se incluye algo de poesía y/o el capítulo correspondiente a la novela de folletín; algunos avisos; se reproducen notas o artículos provenientes de la provincia o el extranjero (37).

Las tertulias fueron espacios donde poco a poco se fraguó la intimidad de sus asistentes. Seguramente la literatura de ese periodo de finales del siglo XIX y comienzos del XX, lo que se ha llamado propiamente "fin de siglo" o decadentismo, hubiera sido otro sin la existencia de esas tertulias, sin la presencia de cafés y bares que cobijaban a sus asistentes. Pacheco describe así esa última década del siglo XIX:

El novecientos fue una década de talento y frivolidad, fervor e irresponsabilidad en que la batalla contra el lugar común se resolvió muchas veces en amaneramiento y neocursilerías; pero también dio algunas obras poéticas que siguen siendo válidas en este otro mundo que es el nuestro, acaso por las dolorosas semejanzas entre las circunstancias actuales y las que rodearon a los modernistas (XLIX).

En México, la historia de estas tertulias está todavía por escribirse, pero su importancia fue al menos tan relevante como las que tuvieron las españolas del Pombo, El Levante, la Granja del Henar, la Cacharrería del Ateneo, etc. Es curioso cómo en México, además, el cambio de sensibilidad y de estética está presidido por la alternancia entre el bar y el café.

Renato Leduc, en un artículo de 1943 para la revista Letras de México, intitulado "El café", habla de la correspondencia entre la infusión y el ambiente donde se consume, haciendo prácticamente imposible separar uno de otro: 
Por otra parte, me causaba cierta perplejidad no saber si la monografía en cuestión debería versar sobre el café considerado como grano, droga, estimulante; sobre el café considerado como establecimiento, tertulia, mentidero y también estimulante; sobre el café considerado como fuente de riqueza o sobre el café considerado como fuente de inspiración.

(Sería interesante dilucidar si el ambiente de café estimula debido a la bebida que allí se sirve o si la bebida que allí se sirve estimula debido al ambiente de café; aunque pienso, este problema podría reducirse a aquel otro problema bio-metafísico de si fue primero la gallina o el huevo [...]) (7).

Alfredo Maillefert, al comienzo de su evocación del duque Job, recrea el ambiente del Café de la Concordia con sus claroscuros entre el refinamiento y el decadentismo, la sofisticación y la sensualidad, el aristocratismo y la modernidad:

Aquí, sentado en un diván rojo del Café de la Concordia, mientras desayuno —-son las ocho-, mientras los meseros vestidos de etiqueta y con blancos mandiles, van y vienen por el ancho salón, adolescente ávido y azorado, he descorrido una cortinilla también de terciopelo rojo y, a través del límpido ventanal, estoy observando, a esta temprana hora de la mańana, el movimiento de la calle: pasan los carros repartidores — de hielo, de cerveza - con sus pesados tiros de caballos normandos, que suenan reciamente los cascabeles de sus colleras. Pasan los coches de bandera azul, vestidos interiormente de gris, y las calandrias de bandera roja o amarilla: alguna, por descuido del auriga, lleva todavía encendida una bujía de la farola (IX-X).

El nostálgico epitafio de La Concordia firmado por Luis. G. Urbina en 1906 acentúa más el aspecto decadente del viejo café: 
Las podridas tapicerías, los marcos de oro muerto, los espejos opacos como grandes ojos agonizantes, los mármoles amarillentos, los terciopelos chafados, los verdes de hoja invernal y los rojos desteñidos y manchados eran como viejas reliquias para nosotros. En aquel pliegue de la cortina, en aquel ornato del espejo, en aquel tritón ridículo de la fuente, en cada escalón de la presuntuosa y marmórea escalera, en el descascarado fresco que representaba la plaza de San Marcos de Venecia, pusimos, cada quien, durante muchos ańos, miradas, remembranzas, memorias, instantes de reflexión o de alegría, minutos de placer o de amargura (94).

La alusión a la decapitación se refiere indudablemente al fin de un periodo, de una etapa de la cultura mexicana que no sólo había concluido con la demolición de La Concordia sino que ya no podía regresar, como la guillotina representa el fin del Antiguo Régimen; pero también es notable que se refiera al café de La Concordia en femenino, lo que revela una relación que va más allá de lo que el local podía ofrecer a su concurrencia. Este café tenía una larga tradición ligada casi siempre a los hombres de letras, periodistas, políticos e intelectuales que se congregaban en torno a sus mesas. Asistieron a sus veladas de manera regular las sucesivas promociones posrománticas y modernistas como Manuel Payno, Ignacio Ramírez; más tarde Manuel José Othón en compañía de Jesús Valenzuela y Alejandro Garrido; Manuel Gutiérrez Nájera, José María Villasana, Manuel Puga y Acal, etc.

Otro café testigo de las veladas de cenáculos y cofradías de poetas y artistas modernistas fue el del Progreso, una extremidad de la Sociedad del Progreso, pero que acabó convertido en su entrańa; el inmueble sufrió una remodelación en 1872 que añadía al salón principal otros dos salones más recogidos y discretos, y cuyo mayor aporte fue un servicio constituido por primera vez por "meseras" (Díaz y 
de Ovando, 2003: 74-75). El Progreso abrió sus puertas el 5 de mayo de 1868, como recoge Clementina Díaz y de Ovando:

Sociedad del Progreso. Café, nevería, fonda y hotel.

Al regresar de Europa el que suscribe, tomó la negociación con cuyo nombre se encabeza este aviso, y con el objeto de ponerla a la altura de los mejores que en su género existen en México y devolverla al crédito que tuvo en sus mejores días no ha omitido gasto ninguno y le ha introducido las mejoras que exigen la cultura y el buen gusto de los habitantes de esta hermosa capital y para lograr su objeto contrató a los mejores artistas de México para el desempeño de las manufacturas de diversos objetos que se consumen en la casa; compró un servicio enteramente nuevo, y los más exquisitos caldos que encontró en el mercado, y dispuso varios gabinetes para señoras y caballeros, en los cuales se sirven, además de los artículos propios de los ramos de café y nevería, carnes frías y meriendas variadas (Rodríguez y Fernández, 2003: 59).

El Progreso, desde ese momento, rivalizó con el Café de la Concordia por hacerse con una parte de su, si no distinguida, por lo menos notable concurrencia. En 1875, con el propósito de recuperar el espacio que había ocupado años antes, el Café del Progreso introdujo la novedad de que el servicio estaba a cargo de meseras, algo desconocido hasta entonces que acusó cierto revuelo (Díaz y de Ovando, 2003: 75). Tanto Antonio García Cubas como Guillermo Prieto han dejado constancia de la evocación de su ambiente, particularmente interesantes son las notas acerca de la concurrencia firmadas por Prieto:

En la tarde, militares y empleados ociosos, vejetes calaveras, tahúres empedernidos, niños finos y polluelos pretenciosos se envolvían en una atmósfera de humo de tabaco y formaban grupos en las mesas, ya de disputadores políticos, ya de obscenos oficiales que escupían por el colmillo y daban alas a la crónica escandalosa, ya de gentes de estas que se dicen decentes, sin oficio ni beneficio, que viven de pa- 
rásitos de su familia, de sus amigos y del erario, que ven como capital enemigo al trabajo honrado (Prieto, en Valle-Arizpe, 1980: 287).

Tahúres, noctívagos, buscavidas son a ojos de Prieto los feligreses habituales de El Progreso, pero más allá de este repertorio, sí conviene subrayar la presencia de exponentes de diferentes profesiones y no profesiones, asiduos de diversas edades, representantes de todo el espectro socioeconómico de México, lo que confirma por lo menos que el café era uno de los pocos espacios donde la estricta separación de castas no se respetaba; al contrario, parecería que su sentido último fuera la abolición precisamente de las diferencias entre sus parroquianos. Los modernistas vivieron la bohemia entre los prostíbulos y los bares, "en los burdeles y las cantinas (el alcoholismo extingue a Couto Castillo a los veintiún años) o bien en los paraísos artificiales, predilectos de la jeunesse doreé que se reúne en el 'Boulevard', la 'Zona Rosa' de entonces: las calles de San Francisco y Plateros, entre el Jockey Club y el Palacio de Iturbide, convertido en hotel" (Pacheco, 1999: XLVIII).

Con el tiempo el café se convirtió en lugar de encuentro habitual para los jóvenes que se iniciaban en la literatura y la política. Octavio Paz, por ejemplo, caracteriza así al grupo que más tarde se llamará Taller: "Entre 1935 y 1938 el observador más distraído podía advertir que una nueva generación literaria aparecía en México: un grupo de muchachos, nacidos alrededor de 1914, se manifestaba en los diarios, publicaba revistas y libros, frecuentaba ciertos cafés y concurría a las salas de teatro experimental" (1994: 95); pero, además, el café y el bar son espacios distintivos que diferencian a este grupo de otros grupos: "Los de Taller frecuentábamos los bares y los cafés; los de Tierra Nueva se reunían en el jardín de la Facultad de Filosofía y Letras" (96). El café y el bar se oponían a la facultad pero detrás de esta afirmación hay algo más que merece destacarse: el grupo de Taller prefería satisfacer su curiosidad con una actitud cercana 
al autodidactismo opuesta a la educación más formal recibida en la academia: espontaneidad e interés personal parecían ser las exigencias que guiaban a los jóvenes de Taller a la mesa de un café o a la barra de un bar, a diferencia del conocimiento más rígido y acartonado también que se recibía en las aulas de la facultad. Pero por paradójico que pueda resultar, Paz apela a la herencia legada por escritores e intelectuales en esas mesas de café, donde de una manera u otra los jóvenes que se reunían recreaban, quizás sin saberlo, aquellas otras entre las que fraguó la tradición literaria mexicana de la primera mitad del siglo XX. Paz es más preciso en otro escrito donde se refiere explícitamente a otro café de la ciudad de México que ha pasado a pertenecer al mundo literario por derecho propio, el Café París de la calle 5 de Mayo donde se reunía con otros contertulios a principios de los años cuarenta:

Creo que los años del Café París han sido el único período en que hemos tenido lo que se ha llamado "vida de café", como en Francia, España e Italia. El café fue una institución literaria que sustituyó al salón. Pero en México no tuvimos salones: los escritores se reunían en algunas librerías y los poetas modernistas en los bares. El Café París fue una sociedad dentro de la sociedad. Asimismo una geografía: cada mesa era una tertulia, cada tertulia una isla y una plaza fortificada. Las relaciones entre las islas eran, al mismo tiempo, frecuentes y arriesgadas. Siempre había algún intrépido —o algún inconsciente- que iba de una mesa a otra. Unos eran mensajeros y otros desertores. Porque había también emigraciones y escisiones. Incluso durante una temporada, cuando fundamos El Hijo Pródigo, acaudillados por Barreda, emigramos del Café París - que se había vuelto demasiado populoso y agitado- y nos establecimos en un café cercano a la calle Bolívar (1991: 120).

Aunque Paz y su grupo acabaron por abandonar el Café París, otras personalidades vinieron a ocupar esas mesas como islas y a dotar de 
sentido ese archipiélago; entre otros, José Gaos, quien hablaba con otros contertulios acerca de: "la creación de una comunidad de poetas, de hombres con altas preocupaciones. Pero esa comunidad está determinada, ya no por valores o por quehaceres comunes sino, precisamente, por la divergencia y la soledad de individuos que ejercen un oficio cada día más ajeno al interés colectivo, a las necesidades de masa" (Fuentes, 1958: 156).

Tomás Segovia, cuya promoción sigue a la de Paz, ha sido otro poeta que ha hecho de la mesa del café un espacio privilegiado para la escritura, la lectura y la conversación amable y cálida: "Los que leíamos entonces a Octavio Paz en Chapultepec o en casa o en los cafés, en voz baja para uno mismo o en voz alta para los amigos, oíamos esa voz íntima pero no privada, sino nuestra, que nos alentaba en una fe que era difícil entonces, la fe en la precedencia de la luz, en el valor inmancable del decir certero, en la inocencia de la verdad" (104). El café y el bar son espacios constituyentes de lo íntimo antes que de lo privado, lugares públicos donde se desarrolla la actividad íntima de la escritura, la lectura y la conversación. En la ciudad, si el paseante la recorre con los ojos de la imaginación, puede encontrar todos los objetos fabricados por el hombre, sobre todo si está atento a ese juego de afinidades que Baudelaire estampó en célebre poema "Correspondencias": descubrir en un rincón la silueta de una famosa escultura, sorprenderse ante una mesa que a su vez puede transformarse en una isla. Detrás de cualquier ciudad hay una ciudad oculta que el caminante curioso y atento persigue descifrar de acuerdo a un código personal, de la misma manera que el escritor codifica ese desciframiento en su página en blanco hasta desvelar esa geografía urbana reescriturada ahora en una orografía íntima, un escaparate del tiempo reconvertido en galería de vidas. 


\section{Bibliografía}

Altamirano, Ignacio Manuel, 1986, Textos costumbristas. Obras completas, México, TV SEP.

Baroja, Ricardo, 1952, Gente del 98, Barcelona, Juventud.

Beezley, William H., 1989, Judas at the Jockey Club and Other Episodes of Porfirian Mexico, Lincoln y Londres, University of Nebraska Press.

Cansinos-Assens, Rafael, 1995, La novela de un literato, t. 3, ed. de Rafael M. Cansinos, Madrid, Alianza Tres.

Contreras García, Irma, 1998, La prosa de Gutiérrez Nájera en la prensa nacional, México, UNAM.

Couto Castillo, Bernardo, 1986, "La canción del ajenjo", en Revista Azul, núm. 5, 31 de mayo, p. 77.

Escalante Gozalbo, Fernando, 1993, Ciudadanos imaginarios. Memorial de los afanes y desventuras de la virtud y apología del vicio triunfante en la república mexicana. Tratado de moral pública, México, El Colegio de México.

Fernández Ledesma, Enrique, 1995, Nueva galería de fantasmas, pról. Vicente Quirarte, México, UNAM.

Fuentes, Carlos, 1958, La región más transparente, México, FCE.

García Cubas, Antonio, 1978, El libro de mis recuerdos. Narraciones históricas, anecdóticas y de costumbres mexicanas anteriores al actual estado social ilustradas con más de trescientos fotograbados, México, Patria.

Gómez de la Serna, Ramón, 1999, Pombo, Madrid, Visor.

González Obregón, Luis, 1991, Las calles de México, pról. José Luis Martínez, México, Alianza Editorial.

Gutiérrez Nájera, Manuel, 1896, “Abshinte”, en Revista Azul, núm. 3, 17 de mayo, p. 45. 
Leduc, Renato, 1942, "El café", en Letras de México, núm. 24, 15 de diciembre, p. 7.

Lozano Herrera, Rubén, 1995, Las veras y las burlas de José Juan Tablada, México, Universidad Iberoamericana.

Maillefert, Alfredo, 1973, "Prólogo", en Gutiérrez Nájera, Manuel, Cuentos, crónicas y ensayos, México, UNAM.

Martínez, José Luis, 1981, “Estar en el mundo, 1889-1910”, en Historia General de México, t. 2, México, El Colegio de México.

Nervo, Amado, 1991, Obras completas, t. 1, pról. Francisco González Guerrero, México, Aguilar.

Pacheco, José Emilio, 1999, Antología del Modernismo (1884-1921), México, Era/UNAM.

Panabière, Louis, 1991, Cité Aigle, Ville Serpent, Perpignan, Press Universitaires de Perpignan.

Paz, Octavio, Convergencias, Barcelona, Seix Barral.

, 1994, “Antevíspera: Taller (1938-1941)”, en Obras completas, t. 4, México, FCE/Círculo de Lectores.

Pérez-Rayón Eluzundia, Nora, 2001, México 1900. Percepciones y valores de la gran prensa capitalina, México, UAM/Miguel Ángel Porrúa.

Rodríguez y Fernández, José, 2003, "Sociedad del Progreso. Café, nevería, fonda y hotel”, en Díaz y de Ovando, Clementina, Los cafés en México en el siglo XIX, México, UNAM.

Segovia, Tomás, 1993, Páginas de ida y vuelta, México, El Equilibrista.

Toussaint, Florence, 1989, Escenario de la prensa en el porfiriato, México, Fundación Manuel Buendía.

Trapiello, Andrés, 1999, "El caso Ramón”, en Gómez de la Serna, Ramón, Pombo, Madrid, Visor. 
Urbina, Luis G., 2003, “Se murió La Concordia”, en Díaz y de Ovando, Clementina, Los cafés en México en el siglo XIX, México, UNAM.

Valle-Arizpe, Artemio del, 1980, Calle vieja y calle nueva, México, Diana/ Gobierno de la Ciudad de México.

VVAA, 1959, Almanaque literario. Espejo del siglo XIX para 1960, México, INBA.

Wilson, Elisabeth, 2000, Bohemians: the Glamorous Outcats, New Brunswick, Rutger.

Zepeda Winkfield, Alfonso, 2001, Alucinaciones, ed. de Ignacio Betancourt, México, El Colegio de San Luis. 